\title{
Treatment of tardive dyskinesia with choline and tetrabenazine
}

\author{
A. P. J. SNELL \\ M.R.C.P., F.R.A.C.P.
}

\author{
Maria Cleary \\ M.B., Ch.B.
}

\author{
M. SAMBROOK \\ M.D., M.R.C.P. \\ University Hospital of South Manchester, Manchester M20 8LR
}

\begin{abstract}
Summary
A patient with severe tardive dyskinesia due to longterm neuroleptic medication is described. The 2 factors immediately precipitating the onset of the disorder appeared to be the administration of benzhexol hydrochloride and the sudden termination of neuroleptic therapy. The disorder was satisfactorily controlled with choline chloride and a small dose of tetrabenazine. The suggested mechanism of tardive dyskinesia is discussed.
\end{abstract}

\section{Introduction}

Tardive dyskinesia is a hyperkinetic, extrapyramidal disorder associated with long-term neuroleptic therapy. The reported prevalence ranges between $0.5 \%$ and $40 \%$ of patients receiving such treatment but the increasing use of these drugs may well be accompanied by a greater incidence in the future. Treatment is often disappointing (Editorial, 1979) but benefit has been reported with choline (Gelenberg, Doller-Wojcik and Growden, 1979) and tetrabenazine (Kazamatsuri, Chien and Cole, 1972). A patient with severe tardive dyskinesia is described who responded well to a combination of choline and tetrabenazine.

\section{Case report}

A 66-year-old woman, developed an anxiety depressive illness which was initially treated with tricyclic antidepressants and ECT. However, in the 4 years before this admission her medication was changed to chlorpromazine $100 \mathrm{mg} 3$ times/day. The first 3 years of this new regime were trouble-free but in the last 12 months the development of symptoms and signs of Parkinsonism necessitated the addition to her treatment of benzhexol hydrochloride $5 \mathrm{mg} 3$ times/day. Soon afterwards the patient complained of unsteadiness and experienced numerous falls, the latter becoming so troublesome that her daughter destroyed all her medications. Two weeks after the sudden cessation of therapy she was unable to walk or sit upright and became bedfast with continuous writhing movements of the face, tongue and limbs. When examined in hospital she had continuous bucco-lingual and facial dyskinesia with choreoathetoid movements of the head, trunk and extremities. She was unable to sit or stand unsupported.

The patient was started on choline powder the dosage being gradually increased over 3 months to $17.5 \mathrm{~g} /$ day until gastrointestinal irritation and a strong, 'fishy' body odour necessitated a reduction in dose to $15 \mathrm{~g} /$ day. The choline greatly reduced the dyskinetic movements and the patient began walking with a gutter frame. Finally, her treatment was supplemented with tetrabenazine $25 \mathrm{mg} 4$ times/day following which her walking improved further and she became virtually free of dyskinetic movements.

\section{Discussion}

Although tardive dyskinesia following long-term neuroleptic therapy has been recognized for some years, treatment remains unsatisfactory. The underlying mechanisms probably involve an imbalance between dopaminergic and cholinergic activity in the striatum due to dopaminergic receptor hypersensitivity. This hypothesis suggests 2 avenues for intervention-raising acetyl choline levels, e.g. with choline or depleting monoamines, e.g. tetrabenazine.

The patient reported here responded well to treatment with choline alone but further improvement occurred with the addition of a small dose of tetrabenazine.

The present case also demonstrates the ability of an anti-cholinergic drug (benzhexol hydrochloride) to release a dyskinetic state masked by the neuroleptic drug. This masking effect may delay the 
appearance of the tardive dyskinesia until it is refractory and it has been proposed that the short administration of an anti-parkinsonian agent may aid the early detection of tardive dyskinesia (Chouinard, de Montigny and Annable, 1979).

\section{Acknowledgments}

We thank Dr Michael Lye for permission to report this case.

\section{References}

Chouinard, G., de Montigny, G. \& Annable, L. (1979) Tardive dyskinesia and antiparkinsonian medication. American Journal of Psychiatry, 136, 228.

EdITORIAL (1979) Tardive dyskinesia. Lancet, ii, 447.

Gelenberg, A.J., Doller-Wojcik, J.C. \& Growden, J.H. (1979) Choline and lecithin in the treatment of tardive dyskinesia: preliminary results from a pilot study. American Journal of Psychiatry, 136, 772.

Kazamatsuri, H., Chien, C. \& Cole, J. (1972) Treatment of tardive dyskinesia. Archives of General Psychiatry, 27, 95 